\title{
İnovasyon Etkenlerinin Araştırılması ve Optimal İnovasyon Portföy Yapılanmasi*
}

Araştırma Makalesi /Research Article

\author{
Melike METERELLIYOZ \\ Tunahan TAYAR ${ }^{2}$
}

ÖZ: Son yıllarda ülke harcamalarında inovasyon yatırımlarının ve buna bağll olarak getiri ve risklerin de arttı̆̆ görülmektedir. Bu durum doğru inovasyon yatırımlarının gerekliliğini ortaya koymaktadır. Bu çalışmada öncelikle Türkiye'de inovasyona uzun dönemli etki eden değişkenleri bulabilmek için yerli patent sayılarının bağımlı değişken olduğu tamamen değiștirilmiş en küçük kareler yöntemi (FMOLS) ile geliştirilmiş modellerde AR-GE harcamalarl, AR-GE personeli sayısı, doğrudan yabancı yatırımlar ve ithalat miktarl etkenler olarak bulunmuştur. Öte yandan inovasyon yatırım kanalının incelenmesi adına AR-GE harcamalarının sektörel bazda yerli patent başvuru sayısına etkileri incelenmiştir. Bu modellerde anlamlı etkiye sahip olan özel sektör, kamu ve yüksekögretim AR-GE harcamaları için harcama oranlart ve tahmin modellerinde elde edilen katsayıları ışı̆̆ında optimal yatırım modeli geliştirilmiştir. Yerli patent başvuru sayısını maksimize etmeyi amaçlayan modellerde, en etkili kanalın yükseköğretim aracılı̆̆lyla AR-GE'ye yatırım yapmak olduğu görülmüştür.

Anahtar Kelimeler: İnovasyon, Patent, AR-GE, Optimal inovasyon portföyü

JEL Kodları: C320, C820, O340

\section{Investigation of Innovation Factors and Optimal Innovation Portfolio Structuring}

\begin{abstract}
Nowadays, innovation investments in expenditures of countries and associated risks and returns have increased. This reveals necessity of correct innovation investments. In this study, firstly, fully modified ordinary least squares models in which domestic patent numbers are dependent variables were developed to find variables that affect innovation in long-term. $R \& D$ expenditures, number of $R \& D$ personnel, foreign direct investment and import amounts were found as significant factors for domestic patent applications. Then, effects of sectoral $R \& D$ expenditures on the number of domestic patent applications were examined. An optimization model was developed for $R \& D$ expenditures through private, public and higher education sector by the help of past expenditure rates and coefficients obtained in regression models. In models aiming to maximize number of domestic patent applications, investing in $R \& D$ through higher education was found as the most effective channel.
\end{abstract}

Keywords: Innovation, Patent, R\&D, Optimal innovation portfolio JEL Codes: C320, C820, O340

Geliş Tarihi / Received: 04/10/2019

Kabul Tarihi / Accepted: 12/03/2020

\footnotetext{
* Bu çalışma, TOBB ETÜ, İ̈BF, İşletme Bölümü’nde Dr. Öğr. Üyesi Melike Meterelliyoz Kuyzu danışmanlığında Tunahan Tayar tarafından yürütülen "İnovasyon Etkenlerinin Araştııılması ve Optimal İnovasyon Portföy Yapılanması" isimli TÜBİTAK 2209-A projesi ile desteklenmiştir.

1 Dr. Öğr. Üyesi, TOBB Ekonomi ve Teknoloji Üniversitesi, İIBF, İşletme Bölümü, mkuyzu@etu.edu.tr, orcid.org/0000-0002-1718-055X

2 Yüksek Lisans Öğrencisi, TOBB Ekonomi ve Teknoloji Üniversitesi, Sosyal Bilimler Enstitüsü, İşletme Anabilim Dalı, t.tayar@etu.edu.tr, orcid.org/0000-0001-7778-1974
} 


\section{Giriş}

Küreselleșen dünyada her ișletmenin kar elde etmesi ve risklerden korunması uzun dönemli sürdürülebilirliği açısından oldukça önemlidir. Karın sağlanması için işletmelerin ürünlerini ve hizmetlerini pazarlarda tutundurabilmesi ve nihayetinde tüketiciye ulaştırabilmesi gereklidir. Ancak hızla gelişen teknoloji ve ekonomik sistemler sebebiyle tüketicilerin ihtiyaçları ve istekleri çok sık değişebilmektedir. Bu durum sonucunda ürün ve hizmet pazarlarında pek çok sektörde yoğun pazar rekabeti hakim hale gelmiştir (Sheth, 1986).

İşletmelerin yoğun rekabet içinde piyasaya tutunabilmeleri için sürekli değişmeleri ve gelişmeleri zorunludur. İşletmeler açısından gelişmenin bir yolu olarak inovasyon yatırımları ön plana çıkmaktadır (Baykal, 2007). Son dönemlerde önemli bir çalışma alanı ve ilgi odağı haline gelen inovasyon ile ilgili ilk kapsamlı çalışmalar Schumpeter tarafından yapılmıştır (Śledzik, 2013). İnovasyonun ekonomik açıdan çok önemli bir faktör olduğunu savunan Schumpeter, kar elde etme amacı güden her şirketin mutlak olarak inovasyon yapması gerektiğini savunmuştur. Ekonomik Gelişme Teorisi ile inovasyonun zorunlu olduğunu dile getiren Schumpeter, inovasyonu 5 ayrı başlık altında incelemiştir. Bunlar; yeni bir ürünü piyasaya sürmek ya da zaten piyasada var olan bir üründe çeşitlilik oluşturmak, üretim süreçlerinde bir yenilik yapmak, yeni bir pazar sahası oluşturmak, yeni bir hammadde ya da tedarik maddesi oluşturabilmek ve tekel piyasayı yıkıcı ya da geliştirici bir yapı oluşturmaktır.

Geniş tanımı verilen inovasyon yatırımları kısaca; ürün, hizmet, üretim, yönetim, vb. süreçlerde yenilikler (inovasyonlar) yaparak değişimi ve iyileşmeyi sürekli hale getirmek olarak tanımlanabilir. Bu nedenle inovasyon kavramı günümüz şirketlerinin sürekli odağında olmak zorundadır. Bu sayede firmaların verimliliğin artırılması ve performanslarının geliştirilmesi aracılığıyla sürdürülebilir rekabet avantajı sağlamalarının önü açılabilecektir (Han, Kim ve Srivastava, 1998; Göker, 2000; Weerawardena ve Mavondo, 2011).

Günümüz ekonomik koşullarında ülkelerin ve hatta işletmelerin inovasyon yatırımları oldukça büyük rakamlara ulaşabilmektedir. Bunun sonucunda elbette büyük getirilerin kazanılması beklenmekte iken aynı zamanda riskleri de artan yatırım miktarlarına bağlı olarak artmaktadır. Bu nedenlerle inovasyon statik bir karar değil; doğru şekilde planlanması, yönetilmesi ve kontrol edilmesi gereken dinamik bir süreç olarak ele alınmalıdır (Kuczmarski, 1996).

Gelişmekte olan ve sürdürülebilir büyümeyi en temel hedeflerinden biri olarak gören Türkiye için inovasyonun önemi yadsınamaz düzeydedir. Kalça ve Atasoy (2008), Türkiye'nin AR-GE yatırımları, patent başvuru sayıları ve büyüme oranları ile diğer ülkeleri karşılaştırarak bir durum analizi yapmışlardır. Çalışmada Türkiye'nin bu değişkenlerle oluşturulan çeşitli oranlar açısından gelişmiş ve bazı gelişmekte olan ülkelere kıyasla zayıf durumda olduğu saptanmıştır. Ayrıca ARGE yatırımları sonunda patent sayılarının artmasının verimlilik açısından önemli 
bir çıktı olacağının altı çizilmektedir. Öte yandan mevcut çalışmada kullanılan veriler açısından bakıldığında sonraki yıllarda AR-GE yatırımlarının yıllara bağlı olarak önemli oranlarda arttığı görülmektedir. Bu da yapılan yatırımlar arttıkça Türkiye'de verimli inovasyon çıktıları elde edebilmek adına planlamaların yapılmasının gerekliliği ortaya koymaktadır.

Mevcut çalışmanın amacı, Türkiye için uzun vadeli inovasyon etkenlerini belirleyerek bu etkenler doğrultusunda geri dönüşü en verimli hale getirecek yatırım karmasını oluşturmaktır. Bu kapsamda ilk olarak Türkiye'deki inovasyonu uzun dönemli etkileyen temel faktörler tamamen değiştirilmiş en küçük kareler (Fully Modified Ordinary Least Squares - FMOLS) yöntemiyle tespit edilmiştir. Ele alınan faktörlere ise literatür araştırması 1şı̆̆ında karar verilmiştir. Mevcut çalışmalar incelendiğinde, inovasyon yatırımları için kullanılan kaynaklar arasında AR-GE harcamaları, AR-GE personelleri, doğrudan yabancı yatırımlar gibi faktörlere rastlanmıştır.

Sonraki adımda ise literatür taramasında uygulamalı ve güncel örneğine rastlanılmayan konu olan başarılı bir inovasyon için bu faktörler aracılığıyla doğru yatırımlar nasıl yapılmalıdır sorusu ele alınmıştır. Bu aşamada lineer programlama yöntemi kullanılmıştır. Literatürde, zaman serilerinin analizinde lineer programlama yönteminin tahmin gücünün yüksek olduğu görülmektedir (Shumway ve Chang, 1977; Mosheiov ve Raveh, 1997). Buradaki amaç; finansal kaynakları daha verimli kullanarak optimal bir yatırım portföyü elde edebilmek için tahminsel bir model oluşturabilmektir. Bu modelden yola çıkılarak riskler daha ölçeklendirilebilir düzeyde tutulabilecektir. Bu durumun sağlanması halinde de yukarıda açıklandığı şekilde küresel piyasalarda rekabetçi ve sürdürülebilir avantajlar sağlanmak adına önemli kararlar başarılı şekilde yönetilebilecektir.

Çalışmanın devam eden bölümlerinde ilk olarak literatür araştırmasına yer verilecektir. Ardından çalışmada kullanılan veri setine değinilecektir. Sonraki iki bölümde, çalışmada yapılan tahmin modeli analizleri ve lineer optimizasyon modelleri detaylı olarak açıklanacaktır. Son olarak ise çalışma sonucunda ulaşılan temel bulgulara, çalışmanın literatür ve uygulama için önemine ve kısıtlılıklarına sonuç bölümünde yer verilecektir.

\section{Literatür Taraması}

İnovasyonu etkileyen temel faktörleri, inovasyonun iyi ve kötü taraflarını araştıran Beck, Chen, Lin ve Song (2016), 32 ülkeyi kapsayan ve 1996-2010 yıllarının verilerini içeren bir çalışma yapmışlardır. En önemli ölçütler olarak AR-GE çalışmalarını ve patent sayılarını ele almışlar ve ek olarak da banka kredileri ile ülkelerin büyüme hızlarını değerlendirmişlerdir. Çalışmanın sonucunda ise kısaca finansal inovasyonun ekonomik büyümeye olumlu katkı sağladığını ancak banka kredileri açısından kriz dönemlerinde yatırımlara daha dikkatli yaklaşılması gerektiğini vurgulamışlardır. 
Panel veri analizi yaptıkları çalışmalarında Porter ve Stern (2000), 1900'lü yılların son dönemine ait verilerle bazı İktisadi İşbirliği ve Gelişme Teşkilatı (OECD) ülkeleri için inovasyon etkenlerini araştırmışlardır. Bu çalışmada bağımlı değişken olarak patent sayıları kullanılırken; bağımsız değişkenler olarak da bilim adamı sayıları, mühendis sayıları, patent stoğu verileri, nüfus, ithalat, ihracat, gayri safi yurt içi hasıla (GSYİH), sermaye, çalışan işgücü ve toplam faktör verimliliği verileri kullanılmıştır. Çalışmanın sonucunda AR-GE sektörü işgücü ve yerel bilgi stoğunun inovasyonu olumlu etkilediği; ithalat ve ihracatın ise olumsuz yönde etkilediği bulunmuştur. $\mathrm{Bu}$ negatif ilişkinin sebebi yazarlar tarafından bilgilerin taklit edilmesinin istenmemesi olarak yorumlanmıştır.

Türkiye'yi de içinde bulunduran bir çalışmasında Varsakelis (2001: 1059-1068), 1989-1995 dönemi verilerini kullanarak inovasyonun etkenlerini araştırmıştır. Araştırmacı bağımlı değişken olarak AR-GE yoğunluğunu; bağımsız değişkenler olarak da dişa açıklık, ulusal kültür endeksi ve fikri mülkiyet hakkı koruma verilerini kullanmıştır. Çalışmada dışa açıklık endeksinin AR-GE yoğunluğu üzerinde anlamlı bir etkisinin olmadığı; fikri mülkiyet hakkı koruma gücünün ve ulusal kültür endeksinin ise AR-GE yoğunluğu üzerinde anlamlı ve pozitif bir etkiye sahip olduğu sonucuna varılmıştır.

Tüylüoğlu ve Saraç (2012: 39-74) gelişmiş ve gelişmekte olan ülkelerdeki inovasyon etkenlerini araştırmak için panel veri analizi yöntemini kullanarak bir çalışma yapmışlardır. 1998-2007 yılları arasındaki verilerin kullanıldığı bu çalışmada bağımlı değişken olarak yerli patent başvuru sayıları; bağımsız değişkenler olarak da kişi başı GSYİH oranı; eğitim, AR-GE harcamaları ve doğrudan yabancı yatırım girişlerinin GSYİH içindeki payı, royalti ve lisans ödemeleri kullanılmıştır. Tahmin için DOLS metodunun kullanıldığı bu çalışmada doğrudan yabancı yatırım girişleri hariç diğer değişkenlerin yerli patent başvuru sayısının üzerinde anlamlı ve pozitif etkiye sahip olduğu sonucuna ulaşılmıştır. Ayrıca, makroekonomik etkenlerin gelişmekte olan ülkeler için gelişmiş ülkelere oranla inovasyon üzerinde daha fazla etkiye sahip olduğu yorumuna ulaşılmıştır.

AR-GE faaliyetleri ve girişimcilerin inovasyon üzerindeki etkilerini araştıran çalışmalarında Mercan, Göktaş ve Gömleksiz (2011), 25 ülke için panel veri analizi yapmışlardır. 2003-2008 yıllarını kapsayan verilerle yapılan çalışmada, patent kabul sayıları bağımlı değişken; kamu, özel sektör, yükseköğretim AR-GE harcamaları ve personel sayıları bağımsız değişkenler olarak kullanılmıştır. Çalışma sonucunda özel sektör ve yükseköğretim AR-GE harcamaları inovasyon üzerinde pozitif ve anlamlı; kamu AR-GE harcamaları ise negatif etkili olarak bulunmuştur. Girişimci sayısının ise inovasyon üzerinde anlamlı bir etkisi bulanamamıştır.

Lenger ve Taymaz (2006: 137-153), Türkiye'de imalat sektöründe yer alan firmaları düşük, orta ve yüksek teknolojili endüstriler olarak gruplandırmışlardır. Aynı firmaları eşdeğer yabancı endüstrilere oranla karşılaştırarak bir sektörel analiz çalışması yapmışlardır. 1995-2000 yılları arasındaki 5 yıllık dönemi 
kapsayan verilerle yapılan çalışmada, orta ve yüksek teknolojili sektörlerde yabancı firmaların daha inovatif oldukları sonucuna ulaşılmıştır. Ayrıca teknolojik yeniliklerin transferi konusunda aktif davranılmasının öneminden bahsedilmiştir.

Türkiye'de AR-GE harcamaları, AR-GE araştırmacı sayısı ve patent gibi inovasyon faaliyetlerinin büyüme ve ihracat ile ilişkisini inceleyen araştırma Sungur, Aydın ve Eren (2016) tarafından yapılmıştır. Nedensellik analizinin uygulandığı çalışmada, 1990-2013 yıllarının verileri kullanılmıştır. Çalışmada sonuç olarak AR-GE ve inovasyon faaliyetlerinin büyüme ve ihracat açısından önemli yere sahip olduğu vurgulanmıştır.

Furman, Porter ve Stern (2002), 17 OECD ülkesinin 1973-1996 yıllarındaki verileriyle ulusların inovasyon kapasiteleri ile ilgili çalışma yapmışlardır. Çalışmada bağımsız değişkenler olarak AR-GE harcaması, kişi başı GSYİH, dış ticaret toplamı ve eğitim harcamaları gibi unsurlar ülkeler için inovasyon altyapı kalitesi başlığı altında toplanmış ve ek olarak bazı kültürel özelliklere yer verilmiştir. Çıktı değişken olarak ise patent sayıları ve milyon kişi başına patent sayısı kullanılmıştır. Çalışmada ülkelere göre her bir bağımsız değişkenin ağırlığının değiştiği ancak her birinin inovasyon bakımından önem arz ettiği raporlanmıştır. Ayrıca bütçe gibi kararların belirlenmesi ile kamu politikalarının etkisinden söz edilmiştir.

Türk işletmelerinin inovasyon süreçlerindeki performanslarına etki eden faktörleri araştıran bir çalışma da Kalay ve Kızıldere (2015) tarafından yapılmıştır. 2010 2012 yıllarına ait verilerin kullanıldığı çalışmada ürün/süreç inovasyonu için teknolojik harcamalar, eğitim, işbirlikleri ve finansal destekler önemli faktörler olarak bulunmuştur. Ek olarak yasal düzenlemelerin ve şirketlerin katı yapılarının da olumsuz faktörler olduğu raporlanmıştır. Ayrıca inovasyonun işletmelerin proaktif olarak rekabet avantajı elde etmeleri için önemli bir unsur olduğu ve kar marjına önemli katkı sağladığı vurgulanmıştır.

İnovasyonun etkenlerini belirlemek için yapılan bir diğer çalışmada Türkiye'yi içeren bazı Asya ülkeleri kullanılmıştır (Malik, 2019). 2008-2017 yılları arasındaki verilerle yapılan çalışmada iki adımlı genelleştirilmiş moment metodu uygulanmıştır. Çalışmada bağımlı değişken olarak patent sayılarına yer verilmiştir. Sonuç olarak kurumsal kalite, eğitim düzeyi ve dış ticaret hacmi değişkenleri olumlu; doğrudan yabancı yatırım ise olumsuz inovasyon faktörü olarak bulunmuştur.

Ben-Horim ve Silber (1977: 277-296) finansal inovasyonu lineer programlama yaklaşımıyla incelemişlerdir. Çalışmada 1952-1972 yıllarının verileri kullanılmıştır. Ayrıca bu çalışmada sadece bankaların yeni finansal varlıklara ne oranda yatırım yapmaları gerektiği üzerinde durulmuştur. Bir diğer lineer programlama çalışmasında ise genel olarak yatırımlar üzerine bir araştırma yapılmıştır (Merville ve Tavis, 1973). Çalışmada karı maksimize etmek için 
yatırımların planlanması adına birkaç farklı hipotetik senaryo üzerinde durulmuştur.

Yukarıda listelenen ve inovasyona etki eden faktörleri inceleyen araştırmalara kıyasla bu çalışmada Türkiye'ye ait veriler çok daha kapsamlı olarak incelenecektir. Ayrıca inovasyon kanallarına doğru yatırımlar nasıl yapılmalıdır konusu ile ilgili bir çalışmaya da yapılan literatür araştırması kısmında rastlanmamıştır. Sadece yukarıda verilen iki çalışmada çıktıyı optimize etmek adına genel yatırımları planlama konusunda teorik yaklaşımlara yer verilmiştir. Ancak çalışmalar tarih itibariyle oldukça eskidir. Yani optimal inovasyon araştırmasını konu alması açısından da bu çalışma literatürde bir ilktir.

\section{Veri Analizi}

Çalışmada kullanılan tüm veriler Tablo 1'de listelenmiştir. Veriler internet üzerinden güvenilir kaynaklardan derlenmiştir (Eurostat Database, 2019; Merkez Bankası, 2019; TPE, 2019; TÜİK, 2018; Worldbank, 2020). Literatürdeki inovasyon çalışmalarında geçen ve en önemli inovasyon ölçütü kabul edilen patent sayıları ve buna etkisi kabul gören AR-GE harcamaları, doğrudan yabancı yatırımlar gibi değişkenlerle ilgili veriler Türkiye özelinde toplanmıştır. Buna ek olarak ise inovasyon konusunda etkiye sahip olabileceği düşünülen diğer veriler de modellerde kullanılmak üzere çalışmaya dahil edilmiştir. Ayrıca sektörel kırılım için özel sektör, kamu kesimi ve yükseköğretim ile ilgili verilere yer verilmiştir. Tüm verilerin ortak bir paydada toplanabilmesi amaciyla her bir yıl için Merkez Bankası tarafından yayınlanmış olan kur fiyatları baz alınarak veriler Türk Lirası (TL) cinsinden hesaplanarak çalışmaya dahil edilmiştir. Harcama kalemlerini enflasyon etkisinden arındırıp reel değerleriyle ifade edebilmek amacıyla Türkiye için yıllık GSYİH Deflatörü ile işlem yapılmıştır. Burada deflatör oranlarının kullanılması tüm fiyat değişikliklerini ifade edebilmek adına önemli bir noktadır (Litra, 2009).

Tablo 1: Çalışmada Kullanılan Tüm Veriler

\begin{tabular}{|l|l|c|}
\hline \multicolumn{1}{|c|}{ Veri } & \multicolumn{1}{c|}{ Birim } & Zaman \\
\hline Toplam Ar-Ge personeli (TZE*) & Kişi & $1990-2016$ \\
\hline GSYİH & MTL* & $1990-2016$ \\
\hline İhracat & MTL & $1990-2016$ \\
\hline İthalat & MTL & $1990-2016$ \\
\hline Toplam AR-GE harcaması, tüm sektörler & MTL & $1990-2016$ \\
\hline Toplam AR-GE harcaması, özel sektör & MTL & $1990-2016$ \\
\hline Toplam AR-GE harcaması, kamu & MTL & $1990-2016$ \\
\hline Toplam AR-GE harcaması, yükseköğretim & MTL & $1990-2016$ \\
\hline Yerli patent başvurusu & Adet & $1990-2016$ \\
\hline Katma değer üretimi & MTL & $1990-2016$ \\
\hline Net doğrudan yabancı yatırım & MTL & $1990-2016$ \\
\hline Kur fiyatları & \$/TL - $€ / T L$ & $1990-2016$ \\
\hline GSYİH deflatörü & Yüzde & $1990-2016$ \\
\hline
\end{tabular}

Not: *TZE: Tam Zamanlı Eşdeğer, *MTL: Milyon TL 


\section{Regresyon Modeli}

$\mathrm{Bu}$ çalışmada Türkiye için inovasyonu etkileyen değişkenleri uzun dönemli etkileri bakımından belirlemek üzere tamamen değiştirilmiş en küçük kareler (FMOLS) yöntemi ile tahmin modelleri oluşturulmuştur. Verilerdeki zaman aralığını genişletmek için herhangi bir tahmin metodu kullanılarak yeni veriler oluşturulmamış, böylece doğrudan reel piyasalarda şekillenmiş veri seti ile çalışılmıştır. Veriler arasında doğrusal olan ilişkilerin görülebilmesi açısından doğal logaritmaları (LN değerleri) alınarak çalışmaya dahil edilmiştir (Benoit, 2011).

Zaman serileri ile analiz yaparken dikkat edilmesi gereken öncelikli husus verilerin durağan oldukları seviyede analize dahil edilmeleridir (Enders, 2015). $\mathrm{Bu}$ koşulu test etmek için hem Augmented Dickey-Fuller hem de Phillips-Perron birim kök testleri kullanılmıştır (Dickey ve Fuller, 1979; Phillips ve Perron, 1988). Bu testlerin sonuçları Tablo 2'de sunulmuştur. Tablo 2'den de görüleceği üzere verilerin 1. farkları alındığında fark verileri durağan hale gelmektedir.

Tablo 2: Birim Kök Testleri Sonuçları

\begin{tabular}{|c|c|c|c|c|}
\hline \multirow[b]{2}{*}{ Veri } & \multicolumn{2}{|c|}{$\begin{array}{c}\text { Augmented Dickey- } \\
\text { Fuller Testi } \\
\end{array}$} & \multicolumn{2}{|c|}{$\begin{array}{c}\text { Phillips-Perron } \\
\text { Testi } \\
\end{array}$} \\
\hline & $\begin{array}{c}\text { Düzey } \\
\text { t-istatistiği }\end{array}$ & $\begin{array}{c}\text { 1. Fark } \\
\text { t-istatistiği }\end{array}$ & $\begin{array}{c}\text { Düzey } \\
\text { t-istatistiği }\end{array}$ & $\begin{array}{c}\text { 1. Fark } \\
\text { t-istatistiği }\end{array}$ \\
\hline $\begin{array}{l}\text { LN[toplam Ar-Ge personeli } \\
\left.\left(\mathrm{TZE}^{*}\right)\right]\end{array}$ & 0,53 & $-5,07 * *$ & 0,53 & $-5,07 * *$ \\
\hline LN[GSYİH] & $-1,98$ & $-5,12 * *$ & 0,57 & $-4,92 * *$ \\
\hline LN[ihracat] & $-0,98$ & $-5,90 * *$ & $-0,93$ & $-6,15^{* *}$ \\
\hline LN[ithalat] & $-1,12$ & $-4,64 * *$ & $-1,09$ & $-5,74 * *$ \\
\hline $\begin{array}{l}\text { LN[toplam AR-GE } \\
\text { harcamas1, tüm sektörler] }\end{array}$ & $-0,42$ & $-6,68 * *$ & $-0,16$ & $-7,09 * *$ \\
\hline $\begin{array}{l}\text { LN[toplam AR-GE } \\
\text { harcamas1, özel sektör] }\end{array}$ & $-0,48$ & $-5,34 * *$ & $-0,45$ & $-5,34 * *$ \\
\hline $\begin{array}{l}\text { LN[toplam AR-GE } \\
\text { harcamas1, kamu] }\end{array}$ & $-0,71$ & $-5,84 * *$ & $-0,46$ & $-6,85 * *$ \\
\hline $\begin{array}{l}\text { LN[toplam AR-GE } \\
\text { harcamas1, yükseköğretim] }\end{array}$ & 0,35 & $-7,93 * *$ & $-0,99$ & $-8,68 * *$ \\
\hline LN[yerli patent başvurusu] & 0,75 & $-3,97 * *$ & 0,56 & $-3,97 * *$ \\
\hline LN[katma değer üretimi] & 0,23 & $-3,98 * *$ & $-0,09$ & $-3,98 * *$ \\
\hline $\begin{array}{l}\text { LN[net doğrudan yabancı } \\
\text { yatırım] }\end{array}$ & $-1,27$ & $-5,49 * *$ & $-1,18$ & $-5,96 * *$ \\
\hline
\end{tabular}

Serilerin farkları alındıktan sonra analize dahil edilmesi uzun dönemli ilişkilerin bulunabilmesi açısından kısıt oluşturmaktadır (Tarı ve Yıldırım, 2009). Bundan dolayı değişkenler arasında uzun dönemli ilişkileri regresyon modellerinde test edebilmek için öncelikle eşbütünleşme analizi yapılmıştır. Eğer değişkenler arasında eşbütünleşme ilişkisi bulunabilirse veriler düzey değerlerinde tahmin modellerine dahil edilebileceklerdir (Gujarati, 1999). Eşbütünleşme analizi için 
Pesaran, Shin ve Smith (2001) tarafından geliştirilen ARDL Sınır testi kullanılmıştır. $\mathrm{Bu}$ yöntemin tercih edilmesinin nedeni de küçük örneklem kümelerinde daha güvenilir sonuçlar vermesidir (Narayan ve Narayan, 2005). Tablo 3'te oluşturulacak her bir tahmin modeli için eşbütünleşme testi sonuçları raporlanmıştır.

Tablo 3'te de görüleceği üzere her bir modelde yer alacak değişkenler arasında $\% 1$ düzeyinde anlamlı derecede eşbütünleşme olduğu tespit edilmiştir. Eşbütünleşmeye sahip verilerde uzun dönemli ilişkileri tahmin etmek için fark almaya gerek kalmadan modern bir yaklaşım olan FMOLS tahmin metodu kullanılabilmektedir (Phillips ve Hansen, 1990). Bu metot ile az sayıda veri olsa dahi güvenilir ve tutarlı sonuçlar elde edilebilmektedir (Bashier ve Siam, 2014).

Tablo 3: ARDL Sınır Testi Uzun Dönem Eşbütünleşme Analizi Sonuçları

\section{F - İstatistiği \\ Sinır Testi Kritik Değerleri (p=0.01) için)}

$\mathbf{I}(\mathbf{0}) \quad \mathbf{I}(\mathbf{1})$

$f$ (LN [yerli patent başvurusu]: LN[toplam Ar-Ge personeli (TZE*)], LN[toplam AR-

Model - 1 GE harcaması, tüm sektörler], LN[GSYİH], LN[ihracat], LN[ithalat], LN[net doğrudan yabancı yatırım], LN[katma değer üretimi])

Model - $2 f$ (LN[yerli patent başvurusu]: LN[toplam AR-GE harcaması, özel sektör])

Model - $3 \quad f$ (LN[yerli patent başvurusu]: LN[toplam AR-GE harcaması, kamu])

Model - $4 f(\mathrm{LN}$ [yerli patent başvurusu]: LN[toplam AR-GE harcaması, yükseköğretim])

$*: p<0,05, * *: p<0,01$.

$\begin{array}{lll}8,53 * * & 3,87 & 5,70 \\ 9,35 * * & 6,03 & 6,76 \\ 8,98 * * & 6,03 & 6,76 \\ & & \\ 12,76 * * & 6,03 & 6,76\end{array}$

İlk FMOLS tahmin modeli (Model-1) ülke düzeyinde inovasyon etkenlerini bulabilmek için yapılmıştır. $\mathrm{Bu}$ modelde bağımlı değişken olarak yerli patent başvuru sayısı kullanılmıştır. Analiz sonuçları Tablo 4'te raporlanmıştır.

Toplam AR-GE personeli sayısı, toplam AR-GE harcaması, net doğrudan yabancı yatırım ve ithalat $\% 1$ anlamlılık düzeyinde anlaml etkenler olarak yerli patent başvuru sayısını tahmin etmektedir. Toplam AR-GE personeli sayısındaki bir önceki yıla göre $\% 1$ artışın yerli patent başvuru sayısını \%2,46 oranında, toplam AR-GE harcamasındaki bir önceki yıla göre $\% 1$ artışın yerli patent başvuru sayısını $\% 0,41$ oranında ve net doğrudan yabancı yatırımdaki bir önceki yıla göre $\% 1$ artışın ise yerli patent başvuru sayısını \%0,1 oranında artıracağı Tablo 4'deki sonuçlarda görülmektedir. Ayrıca ithalattaki bir önceki yıla göre \%1 artışın da yerli patent başvuru sayısını $\% 0,43$ oranında azaltacağ 
görülmektedir. Oluşturulan model ile bağımlı değişken olan yerli patent başvuru sayısındaki sapmaların \%98'i açıklanabilmektedir.

Tablo 4: Yerli Patent Başvuru Sayısı Genel Etkenleri (Model - 1)

\begin{tabular}{|c|c|c|c|}
\hline Bağımsız Değişkenler & Katsayı & t-İstatistiği & Adj. $\mathbf{R}^{2}$ \\
\hline LN[toplam AR-GE personeli] & 2,457 & $10,46 * *$ & \multirow{8}{*}{0,98} \\
\hline LN[toplam AR-GE harcamas1] & 0,414 & $2,89 * *$ & \\
\hline LN[GSYİH] & $-0,843$ & $-1,73$ & \\
\hline LN[net doğrudan yabancı yatırım] & 0,097 & $3,28 * *$ & \\
\hline LN[ihracat] & $-0,218$ & $-1,47$ & \\
\hline LN[ithalat] & $-0,430$ & $-2,98 * *$ & \\
\hline LN[katma değer üretimi] & $-0,183$ & $-0,79$ & \\
\hline (Sabit) & 26,335 & $5,28 * *$ & \\
\hline
\end{tabular}

İnovasyon sürecinde sektörel değerlendirmeler yapabilmek ve çalışmanın ikinci aşamasında kullanılabilmesi için özel, kamu ve yükseköğretim verileri incelenmiştir. $\mathrm{Bu}$ sektörlere ait AR-GE harcamalarının bağımsız değişkenler olarak kullanıldığı modellerde inovasyon çıktısı olarak ise yerli patent başvuru sayısı kullanılmıştır. Tablo 3'te sunulan sonuçlara göre anlamlı olarak eşbütünleşmeye sahip olan bu değişkenler arasında her bir sektör için FMOLS tahmin modelleri oluşturulmuştur. Modellere ait sonuçlar Tablo 5'te sunulmaktadır. Sonuçlardan görüleceği üzere her bir sektör için AR-GE harcaması yerli patent başvuru sayısını anlamlı olarak etkilemektedir. Tablo 5 'te elde edilen sektörel AR-GE harcamalarının katsayıları Bölüm 4'deki optimizasyon modellerinde kullanılmıştır.

Tablo 5:Yerli Patent Başvuru Sayısı ve Sektörel AR-GE Harcamaları Arasındaki İlişki (Model - 2, 3, 4)

\begin{tabular}{|c|c|c|c|c|}
\hline Model & Bağımsız Değişkenler & Katsayı & t-İstatistiği & Adj. $R^{2}(\%)$ \\
\hline \multirow[t]{2}{*}{2} & $\begin{array}{l}\text { LN[özel sektör AR-GE } \\
\text { harcaması] }\end{array}$ & 1,409 & $14,30^{* *}$ & \multirow{2}{*}{0,94} \\
\hline & (Sabit) & $-7,999$ & $-10,85^{* *}$ & \\
\hline \multirow{2}{*}{3} & LN[kamu AR-GE harcamas1] & 1,698 & $19,51 * *$ & \multirow{2}{*}{0,93} \\
\hline & (Sabit) & $-7,963$ & $-14,76 * *$ & \\
\hline \multirow[t]{2}{*}{4} & $\begin{array}{l}\text { LN[yüksek öğretim AR-GE } \\
\text { harcamas1] }\end{array}$ & 2,927 & $20,76^{* *}$ & \multirow{2}{*}{0,95} \\
\hline & (Sabit) & $-20,630$ & $-18,49 * *$ & \\
\hline
\end{tabular}

Geliştirilen modeller eş zamanlı olarak test edilmiştir ve böylece modellerin sorunlarına yönelik düzenlemeler de her modelden sonra giderilmeye çalışılmıştır. Regresyon modellerinin anlamlılık düzeyini değerlendirmek için $p$ değerleri ( $p$ value) incelenmiştir. Her bir modelde hem regresyon geneli için hem de her bir bağımsız değişken için bu değerin literatürde de kabul edildiği üzere 0,05 'ten 
daha küçük bir değer olması koşuluyla nihai modeller oluşturulmuştur (Bland ve Altman, 1995: 170).

Buna ek olarak FMOLS tahmin modellerinde oluşan hataların düzey değerlerinde durağan olması koşulu aranmaktadır (Hansen ve Phillips, 1990). FMOLS modellerinde, klasik tahmin modellerindeki gibi hataların normal dağılıma sahip olması ve değişken varyans sorunu içermemesi gibi şartlar aranmamaktadır (Pedroni, 1996; Gujarati, 2011). Buna rağmen çalışmada ek analiz olarak bu istatistiksel testler de yapılmıştır. Her bir FMOLS modelindeki hatalara ait ilgili değerler Tablo 6'da sunulmuştur.

Tablodaki değerler incelendiği zaman hata terimlerinin düzey değerlerinde en az $\% 5$ anlamlılık düzeyinde durağan olduğu görülmektedir. Bu sonuçlar da tahmin modellerinin gerekli olan şartları sağladığının kanıtıdır. Böylelikle tahmin modellerinde elde edilen katsayıların herhangi bir sorunu içermediğini istatistiksel açıdan söylemek mümkündür.

Tablo 6: Modellerdeki Hataların Varsayımlarına Ait Test Sonuçları

\begin{tabular}{|l|c|c|c|c|}
\hline & $\begin{array}{c}\text { Augmented } \\
\text { Dickey-Fuller } \\
\text { Testi }\end{array}$ & $\begin{array}{c}\text { Phillips- } \\
\text { Perron Testi }\end{array}$ & $\begin{array}{c}\text { Jarque-Bera } \\
\text { Normallik } \\
\text { Testi }\end{array}$ & $\begin{array}{c}\text { Değişken } \\
\text { Varyans }\end{array}$ \\
\hline $\begin{array}{c}\text { Regresyon } \\
\text { Modeli }\end{array}$ & $\begin{array}{c}\text { Düzey t- } \\
\text { istatistiği }\end{array}$ & $\begin{array}{c}\text { Düzey t- } \\
\text { istatistiği }\end{array}$ & t - İstatistiği & Z- İstatistiği \\
\hline Model 1 & $-6,22^{* *}$ & $-6,20^{* *}$ & $1,32^{\#}$ & $1,89^{\#}$ \\
\hline Model 2 & $-2,05^{*}$ & $-2,05^{*}$ & $0,33^{\#}$ & $0,76^{\#}$ \\
\hline Model 3 & $-4,24^{* *}$ & $-4,19 * *$ & $4,67^{\#}$ & $1,61^{\#}$ \\
\hline Model 4 & $-4,16^{* *}$ & $-4,08^{* *}$ & $0,82^{\#}$ & $1,62^{\#}$ \\
\hline$*: p<0,05, * *: p<0,01, \#: p>0,05$ &
\end{tabular}

Ek analizler olarak normalite ve değişken varyans istatistiklerinde ise sıfır hipotezi reddetmek için yeterli düzeyde kanıta sahip olmadıkları görülmektedir. Modeller sonucunda oluşan hatalar normal dağılıma sahiptir. Ayrıca hatalar arasında değişken varyans sorunu da ortaya çıkmamaktadır.

\section{Lineer Programlama Modeli}

Çalışmanın ilk aşamasında inovasyonu etkileyen faktörler FMOLS regresyon metoduyla belirlendikten sonra bu aşamada ise Türkiye içindeki inovasyon yatırımları için optimal bir plan oluşturulması amaçlanmıştır. Amaç fonksiyonu, en önemli inovasyon göstergesi olan yerli patent başvuru sayısının en fazla dönüşünü sağlamak olarak belirlenmiştir. Fonksiyon içindeki belirleyici değişkenler olarak ise en önemli inovasyon etkeni olan doğal logaritması alınmış AR-GE harcamaları kullanılmış ve bu anlamda tüm regresyon analizlerinde anlamlı çıkan sektörel bazdaki kırılımlarından yola çıkılmıştır. 
Tablo 7: Sektörel AR-GE Harcamaların Ortalama Değişim ve Açıklık Değerleri

\section{Özel Sektör Kamu Yükseköğretim}

$\begin{array}{llll}\text { Ortalama \% Değişim } & 7,38 & 6,11 & 7,87 \\ \text { Açıklı } & 3,17 & 2,15 & 1,54\end{array}$

Burada önemli bir husus özel sektör, kamu ve yükseköğretim için amaç fonksiyonunda kullanılacak olan katsayıları belirlemektir. Bunun için sektörel harcama verilerinin değişim ortalamasına ve açıklık değerlerine bakılarak FMOLS tahmin modellerinde elde edilen katsayıların kullanılmasına karar verilmiştir (Tablo 7).

Lineer programlama için ilk aşama olan amaç fonksiyonu belirlendikten sonra modeldeki değişkenler için kısıtlar belirlenmiştir. İlk olarak toplam AR-GE harcaması için miktar kısıtı belirlenmiş ve bu kısıtı kullanarak aynı zamanda farklı risk senaryolarının da kurgulanması sağlamıştır. Bu senaryolar için beklenen büyüme hedeflerine de bakılarak son yıllardaki AR-GE harcamaları çeşitli artış ve azalış durumları göz önünde bulundurularak model çalıştırılmıştır. Modelde kullanılan diğer kısıtlar ise toplam AR-GE harcamasının hangi oranlarda bu üç sektöre dağıtılacağ 1 hususudur. $\mathrm{Bu}$ oranlar için özel sektör, yükseköğretim ve kamu AR-GE harcamalarının değişim miktarlarının toplam AR-GE harcamasındaki değişime oranlarının ortalaması belirlenerek kısıt olarak modele eklenmiştir. Oluşan oranlar ise şu şekildedir: Özel sektör \%58, kamu \%23, yükseköğretim \%19.

Yapılan bu işlemler sonrasında karar değişkenleri, amaç fonksiyonu ve kısıtlar aşağıdaki Model 1'deki gibi oluşturulmuştur. Bu model ile Türkiye için yapılan toplam AR-GE harcamasını üç sektör kanalı üzerinden en uygun yolla dağıtarak en iyi inovasyon göstergelerinden biri olan yerli patent başvuru sayısının en yüksek dönüş oranını sağlamak amaçlanmıştır. Burada hatırlatılması gereken bir önemli husus sektörel analizler için yapılan FMOLS tahmin modellerinde doğal logaritma dönüşümünün yapılmış olmasıdır. $\mathrm{Bu}$ da modelin yorumlamasını değiştirmekte olup, model ile harcama kalemlerine ayrılacak miktarların bir önceki yıla göre yüzde değişimleri ve bu değişimlerin yerli patent başvuru sayısının bir önceki yıla göre yüzde değişimini en optimal olarak nasıl etkilediğine bakılmıştır.

\section{Model 1:}

Karar Değiškenleri:

$X_{l}$ : LN[özel sektör AR-GE harcaması]

$X_{2}$ : LN[yükseköğretim AR-GE harcamas1]

$X_{3}$ : LN[kamu AR-GE harcamas1]

Amaç Fonksiyonu:

$\overline{\operatorname{Max} Z \text { LN (yerli patent başvuru sayıs1) }}=1,41 * X_{1}+2,93 * X_{2}+1_{x} 7 * X_{3}$ 
Kisitlar:

$X_{1}+X_{2}+X_{3} \leq$ Risk durumuna göre belirlenen toplam AR-GE harcama miktarındaki yüzde

$X_{1}-\left[\left(X_{1}+X_{2}+X_{3}\right) * 0,58\right]=0$ değişim

$X_{2}-\left[\left(X_{1}+X_{2}+X_{3}\right] * 0,19\right]=0$

$X_{3}-\left[\left[X_{1}+X_{2}+X_{3}\right] * 0,23\right]=0$

$X_{n_{s}} X_{2_{2}}, X_{3} \geq 0$

Oluşan modelin amaç fonksiyonu üzerinden çeşitli büyüme durumları için risk analizi değerlendirmeleri yapıldıktan sonra buna bağlı olarak Türkiye ekonomisinin genel durumunun yerli patent başvuru sayısına etkisi incelenmiştir. Ardından, harcama kanallarına ayrılan maksimum oranlar için de optimal bir düzenleme kısıtı eklenerek regresyon metodu ve yapılan oranlama çalışması sonucunda her bir harcama kalemi için saptanan katsayıları değiştirmeden en iyi geri dönüş oranını sağlayan harcama düzeni araştırılmıştır. Bu anlamda geliştirilecek olan 3 farklı model ile farklı büyümeler ve düzenlemeler ile yerli patent başvurusu sayısının nasıl değişeceğinin analizi yapılmıştır.

Yapılan ilk çalışmada yukarıda da belirtildiği üzere farklı büyüme oranlarında nasıl bir harcama planı yapılması gerektiği ve bunun patent başvuru sayısındaki değişime etkisi incelenmiştir. Büyüme oranları üzerinden toplam AR-GE harcamasındaki değişim miktarını belirlemek adına son ortalama değişim oranı hesaplanmış ve bu oran $\% 8,47$ olarak saptanmıştır. Ortalama büyüme oranından yola çıkılarak $\% 0, \% 5$ ve $\% 8$ büyüme senaryoları değerlendirilmiştir. Belirlenen senaryolar ile lineer model çözümlenmiş ve sonuçlar Tablo 8'de gösterilmiştir.

Tablo 8: Model 1 Optimal Sonuçları

\begin{tabular}{|c|c|c|c|c|}
\hline $\begin{array}{c}\text { Büyüme } \\
\text { Oranı (\%) }\end{array}$ & $\operatorname{Max} \boldsymbol{Z}$ & $\boldsymbol{X}_{\boldsymbol{I}}$ & $\boldsymbol{X}_{\mathbf{2}}$ & $\boldsymbol{X}_{\mathbf{3}}$ \\
\hline $\mathbf{0}$ & 0,00 & 0,000 & 0,000 & 0,000 \\
\hline $\mathbf{5}$ & 0,09 & 0,029 & 0,010 & 0,011 \\
\hline $\mathbf{8}$ & 0,14 & 0,046 & 0,015 & 0,019 \\
\hline
\end{tabular}

$\mathrm{Bu}$ tablo; toplam AR-GE harcamasındaki artışın büyüme oranlarıyla doğru orantılı bir şekilde artacağı varsayılarak ve geçmiş verilerdeki dağıtım ortalaması hesaba katılarak, bu oranlarla belirlenen üç dağıtım kanalı olan özel sektör, kamu ve yükseköğretim kalemlerine yapılacak dağıtımdan nasıl bir patent geri dönüşü elde edileceğini göstermektedir.

Eğer $\% 0$ büyüme gerçekleşecek olur ise AR-GE harcamasının bir önceki yıla göre değişmeyeceği ve buna bağlı olarak da yerli patent başvuru sayısında da bir önceki yıla göre bir değişim olmayacağı öngörülmüştür. Eğer AR-GE harcamasındaki büyüme oranı \%5 olursa; bu artışın \%2,9'u özel sektör, \%1'i yükseköğretim ve \%1,1'i de kamu aracılığıyla harcanacaktır. Bu harcama dağılımı sonucunda yerli patent başvuru sayısı da bir önceki yıla göre $\% 9$ oranında artacağ1 öngörülmüştür. Eğer AR-GE harcamasındaki büyüme oranı \%8 olursa; bu artışın \%4,6'u özel sektör, \%1,5'i yükseköğretim ve \%1,9'i de kamu aracılığıly harcanacaktır. Bu harcama dağılımı sonucunda yerli patent başvuru sayısının da 
bir önceki yıla göre \%14 oranında artacağı öngörülmektedir. Tüm bu analizler sonucunda Türkiye'nin büyüme oranlarına bağlı olarak AR-GE harcaması üzerinden özel sektör, kamu ve yükseköğretiminde bir önceki yıla göre yapılacak artışların yerli patent başvuru sayısını da regresyon modeline bağlı belirlenen katsayıların 1şığında artıracağı gözlemlenmiştir. Burada dikkat edilmesi gereken sonuç, inovatif yatırımların geri dönüşünün artışının sürdürülebilir olması için, Türkiye'nin büyüme oranına bağlı olarak AR-GE harcamalarına da artan oranlarda pay ayrılması gerekliliğidir.

Son aşamada yapılan çalışmada ise özel sektör, kamu ve yükseköğretim AR-GE harcamalarının yüzde değişimlerinin toplam AR-GE harcaması yüzde değişimi içindeki paylarının optimal olarak belirlenmesi için yukarıdaki optimizasyon modelinde şu değişiklikler yapılmıştır:

- Modele karar değişkenleri olarak $A_{1}, A_{2}$ ve $A_{3}$ değişkenleri eklenmiştir. $\mathrm{Bu}$ değişkenler sırasıyla toplam AR-GE harcamasındaki değişimlerin; özel sektör, yükseköğretim ve kamu için ayrılacak paylarını ifade etmek amaciyla modele dahil edilmiştir.

- Eklenen bu değişkenlerin toplamını 1'e eşitleyen bir kısıt eklenerek önceki modelde yer alan ve geçmiş yıllardaki oranlara göre belirlenen harcama oranları kaldırılarak bu üç kanala yapılan harcama dağılımı modele bırakılmıştır.

Yapılan bu değișiklikler ile daha önce geçmiş ortalama oranlara göre özel sektör, yükseköğretim ve kamuya dağıtılan toplam AR-GE harcamasının, yerli patent başvuru sayısını en çok sayıya çıkarak şekilde model tarafından belirlenmesi sağlanmıştır. Bu durumda oluşan yeni optimizasyon modeli (Model 2) aşağıdaki gibi oluşturulmuştur:

\section{Model 2:}

Karar Değișkenleri:

$X_{I}$ : LN[özel sektör AR-GE harcamas1]

$X_{2}$ : LN[yükseköğretim AR-GE harcamas1]

$X_{3}$ : LN[kamu AR-GE harcamas1]

$A_{1}$ : Özel sektör AR-GE harcamasındaki yüzde değişimin toplam içindeki payı

$A_{2}$ : Yükseköğretim AR-GE harcamasındaki yüzde değişimin toplam içindeki payı

$A_{3}$ : Kamu AR-GE harcamasındaki yüzde değişimin toplam içindeki payı

Amaç Fonksiyonu:

Max Z LN (yerli patent başvuru sayıs1) $=1,41 * X_{1}+2,93 * X_{2}+1,7 * X_{3}$

Kisitlar:

$X_{1}+X_{2}+X_{3} \leq$ Risk durumuna göre belirlenen toplam AR-GE harcama miktarındaki yüzde

$\left.X_{1}-\left[X_{l}+X_{2}+X_{3}\right) * A_{l}\right]=0$ değişim

$\left.X_{2}-\left[X_{1}+X_{2}+X_{3}\right) * A_{2}\right]=0$

$\left.X_{3}-\left[X_{1}+X_{2}+X_{3}\right) * A_{3}\right]=0$

$A_{1}+A_{2}+A_{3}=1$ 
Model 2 çözümlendiğinde aşağıda verilen Tablo 9'daki optimal sonuçlar bulunmuştur.

Tablo 9: Model 2 Optimal Sonuçları

\begin{tabular}{|c|c|c|c|c|c|c|c|}
\hline $\begin{array}{c}\text { Büyüme } \\
\text { Oranı } \\
(\boldsymbol{\%})\end{array}$ & $\boldsymbol{M a x} \boldsymbol{Z}$ & $\boldsymbol{X}_{\boldsymbol{1}}$ & $\boldsymbol{X}_{\mathbf{2}}$ & $\boldsymbol{X}_{\mathbf{3}}$ & $\begin{array}{c}\boldsymbol{A}_{\boldsymbol{1}} \\
(\boldsymbol{\%})\end{array}$ & $\begin{array}{c}\boldsymbol{A}_{\mathbf{2}} \\
(\boldsymbol{\%})\end{array}$ & $\begin{array}{c}\boldsymbol{A}_{\mathbf{3}} \\
(\boldsymbol{\%})\end{array}$ \\
\hline $\mathbf{0}$ & 0,00 & 0,00 & 0,00 & 0,00 & 0 & 0 & 0 \\
\hline $\mathbf{5}$ & 0,15 & 0,00 & 0,05 & 0,00 & 0 & 100 & 0 \\
\hline $\mathbf{8}$ & 0,23 & 0,00 & 0,08 & 0,00 & 0 & 100 & 0 \\
\hline
\end{tabular}

Tablo 9, yine sırasıyla $\% 0, \% 5$ ve $\% 8$ büyüme için toplam AR-GE harcamasındaki bir yıl önceye göre yüzde artışlarının olacağını varsayarak oluşturulmuştur. $\mathrm{Bu}$ artışın hangi kanala dağıtılacağının modele bırakılmasının sonucunda ise tüm değişimin yükseköğretim üzerinden AR-GE'ye aktarıldığı görülmektedir. AR-GE harcamasındaki $\% 5$ artışın tamamının yükseköğretimce kullanılması ile yerli patent başvuru sayısının bir önceki yıla göre \%15 artacağı; \%8'lik artışın tamamının yükseköğretimce kullanılması ile ise yerli patent başvuru sayısının bir önceki yıla göre \%23 artacağı öngörülmektedir.

$\mathrm{Bu}$ analizde görülen durum tüm harcama artışının yükseköğretim tarafından kullanılmasıdır. Bunun nedeni, Model 1'e göre belirlenen katsayılarda yükseköğretim AR-GE harcamasının kamu ve özel sektör tarafından yapılan ARGE harcamalarına göre daha büyük etkiye sahip olmasıdır. Bunun sonucunda ise en uygun geri dönüşü sağlayabilmek adına bu üç kanala dağıtımının modele bırakıldığında tüm yatırım artışının yükseköğretime aktarılmasının en olumlu sonucu sağlayacağı görülmektedir.

$\mathrm{Bu}$ durumun ilk nedeni çalışmada inovasyon göstergesi olarak belirlenen yerli patent başvuru sayısının kullanılması olarak yorumlanabilir. Literatürde sıkça kullanıldığı için ve son modelde her üç sektör için de ortak olabilmesi adına bu istatistik kullanılmıştır. Ancak kamu kuruluşlarında ilk ve öncelikli olarak belirlenen hedeflerde patent başvurusu yapmak veya patent üretmek olmayabilir. Özel sektör ve yükseköğretime oranla daha bürokratik bir yapıda olan kamu kuruluşlarında inovasyon adına süreç iyileştirme çalışmaları yaygın olarak yapılmaktadır. Özel sektöre bakıldığında ise elbette pek çok büyük ölçekli özel şirketin patent başvurusunda çok başarılı olduğu söylenebilir. Ancak Türkiye'de yer alan şirketler verimlilik açısından Avrupa ve Amerika'ya oranla geride kalmaktadır. Buna ek olarak Türkiye'deki özel şirketlerin çok büyük bir bölümünün mikro ve küçük ölçekli olması da bu sonucun bir nedenidir.

Model 1 ve 2 sonuçlarına göre inovasyon çıktısı olarak yerli patent başvurusu ve yatırım olarak da AR-GE harcamalarının kullanıldığ 1 durumda, kamu ve özel 
sektörde verim artırıcı çalışmalar yapılması gerekliliği görülmektedir. Bu modelin sonucunda göze çarpan bir durum da harcama kanallarının en iyi geri dönüşü sağlamak adına modele bırakılmasının, yani Model 2'nin patent başvuru sayısında Model 1'e göre daha başarılı sonuç vermesidir. Model 1'de \%5 büyüme durumunda yapılan AR-GE harcamasındaki artış yatırımı yerli patent başvuru sayının önceki yıla göre \%9 artırırken Model 2'de bu oran \%15'e ulaşmıştır. Aynı şekilde Model 1'de \%8 büyüme senaryosunda yerli patent başvurusu sayısı en fazla \%14 artırılabilirken Model 2 ile bu oran \%23'e kadar ulaşabilmektedir.

Ancak tüm AR-GE harcamalarının yükseköğretime aktarılması ülkeler açısından olası bir durum değildir. Bu durumu daha gerçek hayata yaklaştırabilmek adına politikalar üzerinden lineer modelin oluşturulduğu yıl için toplam AR-GE harcama bütçesindeki değişimin en az \%20'sinin kamu kuruluşlarınca ve en az \%30'unun da özel sektör kuruluşlarınca harcanmasının belirlendiğini varsayarak bir model oluşturulmuştur. Böylece bir önceki durumda oluşan tüm harcama değişiminin yükseköğretim aracılığıyla yapılmasının en iyi dönüşü getireceği kararına etkisini de incelemek mümkün olacaktır. Böylelikle oluşturulacak Model 3'deki karar değişkenleri, kısıtları ve amaç fonksiyonu aşağıdaki gibi belirlenmiştir:

\section{Model 3:}

$\underline{\text { Karar Değișkenleri: }}$

$X_{1}$ : LN[özel sektör AR-GE harcamas1]

$X_{2}$ : LN[yükseköğretim AR-GE harcaması]

$X_{3}$ : LN[kamu AR-GE harcamas1]

$A_{1}$ : Özel sektör AR-GE harcamasındaki yüzde değişimin toplam içindeki payı

$A_{2}$ : Yükseköğretim AR-GE harcamasındaki yüzde değişimin toplam içindeki payı

$A_{3}$ : Kamu AR-GE harcamasındaki yüzde değişimin toplam içindeki payı

Amaç Fonksiyonu:

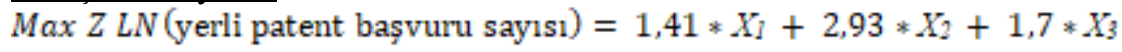

$\underline{\text { Kisitlar: }}$

$\frac{X_{1}+X_{2}}{X_{3}} \leq$ Risk durumuna göre belirlenen toplam AR-GE harcama miktarındaki yüzde

$\left.X_{l}-\left[X_{l}+X_{l}+X_{g}\right) * A_{l}\right]=0$ değişim

$X_{2}-\left[\left(X_{1}+X_{2}+X_{3}\right) * A_{2}\right]=0$

$\left.X_{3}-\left[X_{1}+X_{2}+X_{3}\right] * A_{3}\right]=0$

$A_{1}+A_{2}+A_{g}=1$

$A_{1} \geq 0,30$

$A s \geq 0,20$

$A_{s_{n}} A_{3}, A_{3} \geq 0$

$X_{\Omega_{3}} X_{2}, X_{3} \geq 0$

$A_{1}$ ve $A_{3}$ karar değişkenlerine eklenen en az harcama kısıtının lineer modelin çalıştırılması ile hem dağıtım oranlarına hem de yerli patent başvurusu sayısındaki değişimine etkisi Tablo 10'da özetlenmiştir. 
Tablo 10: Model 3 Optimal Sonuçları

\begin{tabular}{|c|c|c|c|c|c|c|c|}
\hline $\begin{array}{c}\text { Büyüme } \\
\text { Oranı } \\
(\boldsymbol{\%})\end{array}$ & $\operatorname{Max} \boldsymbol{Z}$ & $\boldsymbol{X}_{\boldsymbol{I}}$ & $\boldsymbol{X}_{\mathbf{2}}$ & $\boldsymbol{X}_{\mathbf{3}}$ & $\begin{array}{c}\boldsymbol{A}_{\mathbf{1}} \\
(\boldsymbol{\%})\end{array}$ & $\begin{array}{c}\boldsymbol{A}_{\mathbf{2}} \\
(\boldsymbol{\%})\end{array}$ & $\begin{array}{c}\boldsymbol{A}_{\mathbf{3}} \\
(\boldsymbol{\%})\end{array}$ \\
\hline $\mathbf{0}$ & 0,00 & 0,000 & 0,000 & 0,000 & 0 & 0 & 0 \\
\hline $\mathbf{5}$ & 0,11 & 0,015 & 0,025 & 0,010 & 30 & 50 & 20 \\
\hline $\mathbf{8}$ & 0,17 & 0,024 & 0,040 & 0,016 & 30 & 50 & 20 \\
\hline
\end{tabular}

Buna göre $\% 5$ ve $\% 8$ büyüme senaryolarına göre oluşacak olan AR-GE harcamasındaki artışların özel sektör ve kamuya ayrılan kısmı sadece belirlenen minimum kısıt kadarıdır. Bu harcamanın geri kalan tüm kısmı yine tamamen yükseköğretime bırakılmıştır. \%5 Büyüme durumunda gerçekleşecek olan toplam AR-GE harcaması artış oranının \%30'luk kısmı özel sektör ve \%20'lik kısmı da kamu kesimi eliyle AR-GE çalışmalarına yatırılacaktır. Geriye kalan \%50'lik harcama artışı ise yükseköğretim aracılığıyla AR-GE yatırımı olarak kullanılacaktır. Bu durumun sonucu olarak yerli patent başvurusu sayısı bir önceki yıla göre \%11 oranında artırılabilecektir. Ekonominin \%8 büyümesi durumunda oluşacak olan AR-GE harcaması değişimi yine aynı şekilde eklenen iki kısıtın minimum oranlarınca özel sektör ve kamuya aktarılmıştır. Buna göre özel sektör AR-GE harcaması değişimi bir önceki yıla göre \%2,4, kamu AR-GE harcaması değişimi ise \%1,6 artacak olup geriye kalan oran olan \%4'lük artış da yükseköğretim tarafından kullanılacaktır. Modele göre $\% 8$ büyüme ile oluşan bu dağıtıma göre yerli patent başvuru sayısı önceki yıla göre $\% 17$ oranında artacaktır.

Model 2'de oluşan tüm AR-GE harcaması artışının yükseköğretim aracılığıyla kullanılması durumu bu modele göre değişmiştir. Ancak özel sektör ve kamu kesimine ayrılan kısımlar sadece kısit olarak eklenen ve toplam AR-GE harcamasının \%50'lik bölümünü oluşturan bölümdür. Geriye kalan \%50'lik kısım ise model tarafından tamamen yükseköğretime ayrılmıştır. Model 2'de oluşan tüm AR-GE harcaması artışının en iyi dönüş adına yükseköğretime aktarılmasının gerçek hayata ve ekonomi politikalarına göre gerçekleştirilebilecek bir durum değildir. Bu noktadan yola çıkılarak oluşturulan Model 3'e göre özel sektör ve kamuya yapılan harcamalar modelde belirlenen en az oranda yapılmış ve bu şekilde en fazla yerli patent başvurusunu sağlamak adına kalan kısım da yükseköğretime aktarılmıştır. Bu durumun temel sebepleri yine bir önceki modelde açıklandığı gibi bu çalışmada kullanılan değişkenler veya özel sektör ve kamunun patent başvuruları açısından yükseköğretime göre farklı öncelikleri olması olabilir.

\section{Sonuç}

$\mathrm{Bu}$ çalışma kapsamında araştırılan temel konu Türkiye'de inovasyonu etkileyen faktörler nedir ve doğru inovasyon için nasıl bir finansal yatırım yapılmalıdır sorusudur. Dünya genelinde önemli bir kavram haline gelen inovasyon, şuan gelişmekte olan ülkeler arasında yer alan Türkiye için de oldukça önemli bir 
yerdedir ve üzerinde çok fazla çalışma yapılmıştır. Yapılan araştırmalar kapsamında önemli bir inovasyon göstergesi olan patent sayılarını etkileyen önemli etkenlerin neler olduğu sorgulanmıştır.

Bu çalışma ile de Türkiye için inovasyonu etkileyen önemli faktörler araştırılırken yerli patent başvuru sayısına uzun dönemde etki eden değişkenler FMOLS tahmin yöntemi ile araştırılmıştır. Oluşan sonuçlara göre AR-GE harcamaları, AR-GE çalışanları ve doğrudan yabancı yatırım anlamlı ve pozitif faktörler olarak bulunmuştur. Bunun yanında ithalat ise anlamlı ve negatif bir etken olarak bulunmuştur. $\mathrm{Bu}$ sonuçlar literatür taraması bölümünde sunulan sonuçlarla benzerlik göstermektedir. Sektörel anlamda ise AR-GE harcamaları yine özel sektör, kamu ve yükseköğretim kesimlerinde oldukça önemli bir inovasyon girdisidir ve anlamlı ve pozitif etkiye sahip bir etkendir. Türkiye'de inovasyona olumlu katkılar yapabilmek ve inovatif anlamda gelişmeler yapabilmek adına bu alanlarda yatırımlara önem verilmelidir.

Çalışmanın ikinci bölümünde ise Türkiye adına henüz üzerinde çalışılmamış bir konu olan inovasyon etkenlerine nasıl yatırım yapılması gerektiği bir optimizasyon modeli ile araştırılmıştır. Burada çeşitli büyüme senaryoları aracılığıyla riskler göz önüne alınarak toplam AR-GE harcama bütçesinin özel sektör, kamu ve yükseköğretime nasıl dağıtılması gerektiği üzerinde durulmuştur. Sonuç olarak ise tüm bu üç sektöre ayrılacak olan yatırımların da yerli patent başvurusu üzerinde olumlu etkileri olacağı bulunmuştur. $\mathrm{Bu}$ anlamda öngörülen büyüme rakamları değerlendirilerek, bu rakamlara orantılı şekilde AR-GE harcamaları da üç sektör üzerinden olumlu inovasyon etkenleri olarak görülmüştür.

İnovasyon göstergesi olan patent üretebilme konusunda yükseköğretimin en verimli sektör olduğu, optimizasyon modelleriyle görülmüştür. $\mathrm{Bu}$ durum yükseköğretim kesimindeki teorik bilgi kapasitesinin önemini ortaya çıkarmaktadır. Bunun yanında diğer önemli kanallar olan kamu ve özel sektörlerde de teorik bilgi kapasitesini artırmak amacıyla yükseköğretim ve sanayi işbirliğinin geliştirilmesi gerekliliği ortaya çıkmaktadır. Öte yandan inovasyon çıktı göstergesi olarak yerli patent başvurusu alınması da bu sonucun bir nedeni olabilir ve farklı sektörler için farklı göstergelerin değerlendirilmesi gerekliliği de ortaya çıkmıştır. Ek olarak optimal inovasyon yatırım analizi Türkiye için yeni bir alandır. $\mathrm{Bu}$ nedenle sunulan veriler uzun vadeli ve bağımlı optimizasyon modelleriyle çalışmak için henüz yeterli değildir, fakat bu bilinç oluştukça önümüzdeki yıllar için çok daha detaylı ve sürdürülebilir modeller üzerinde çalışılacaktır. 


\section{Kaynakça}

Bashier, A. A. ve Siam, A. J. (2014). Immigration and Economic Growth In Jordan: FMOLS Approach. International Journal of Humanities Social Sciences and Education (IJHSSE), 1(9), 85-92.

Baykal, B. (2007). İnovasyon ve Sürdürülebilir Kalkınma İlişkisi: Türkiye. Marmara Üniversitesi Sosyal Bilimler Enstitüsü Yayımlanmamış Yüksek Lisans Tezi, İstanbul.

Beck, T., Chen, T., Lin, C., ve Song, F. M. (2016). Financial Innovation: The Bright and The Dark Sides. Journal of Banking \& Finance, 72, 28-51.

Ben-Horim, M. ve Silber, W. L. (1977). Financial Innovation: A Linear Programming Approach. Journal of Banking \& Finance, 1(3), 277-296.

Benoit, K. (2011). Linear Regression Models with Logarithmic Transformations. London School of Economics, London, 22(1), 23-36.

Bland, J. M. ve Altman, D. G. (1995). Multiple Significance Tests: The Bonferroni Method. Bmj, 310(6973), 170.

Dickey, D. A. ve Fuller, W. A. (1979). Distribution of The Estimators for Autoregressive Time Series with A Unit Root.Journal of the American Statistical Association, 74(366a), 427-431.

Enders, W. (2015). Applied Econometric Time Series (Fourth Edition), Wiley.

Eurostat Database. (2019). https://ec.europa.eu/eurostat/data/database. (Erişim: 14.03.2019).

Furman, J. L., Porter, M. E. ve Stern, S. (2002). The Determinants of National Innovative Capacity. Research Policy, 31(6), 899-933.

Göker, A. (2000). Prodüktivite, Inovasyon Yeteneği ve Teknoloji. MPM, "Rekabet Gücü, Teknoloji ve Verimlilik”, Tartışmalı Toplantı, MPM, Ankara, 25.

Gujarati, D. N. (2011). Econometrics by Example, Mc-Graw Hill. (No. 330.015195 G84.).

Gujarati, D. N. (1999). Temel Ekonometri (Basic Econometrics), İstanbul: Literatür Yayıncılık.

Han, J. K., Kim, N. ve Srivastava, R. K. (1998). Market Orientation and Organizational Performance: Is Innovation A Missing Link?. Journal of Marketing, 62(4), 30-45.

Hansen, B. E. ve Phillips, P. C. (1990). Estimation and Inference in Models of Cointegration: A Simulation Study. Advances in Econometrics, 8(1989), 225248. 
Kalay, F. ve Kızıldere, C. (2015). Türk İşletmelerinin İnovasyon Performansını Etkileyen Faktörler Üzerine Bir Araştırma. ODÜ Sosyal Bilimler Araştırmaları Dergisi (ODÜSOBİAD), 5(13), 36-63.

Kalça, A. ve Atasoy, A. G. Y. (2008). Ekonomik Büyüme Aracı Olarak Bilgi Yayılımları ve İnovasyon. Bilgi Ekonomisi ve Yönetimi Dergisi, 3(2), 95-110.

Kuczmarski, T. D. (1996). What Is Innovation? The Art of Welcoming Risk. Journal of Consumer Marketing, 13(5), 7-11.

Lenger, A. ve Taymaz, E. (2006). To Innovate or To Transfer?. Journal of Evolutionary Economics, 16(1-2), 137-153.

Litra, A. (2009). The Inflation Rate Determined as A Change in The GDP Deflator and in CPI. Bulletin of the Transilvania University of Brasov. Economic Sciences. Series V, 2, 207.

Malik, S. (2020). Macroeconomic Determinants of Innovation: Evidence from Asian Countries. Global Business Review, 0972150919885494.

Mercan, B. Göktaş, D. ve Gömleksiz, M. (2011). Ar-Ge Faaliyetleri ve Girişimcilerin İnovasyon Üzerindeki Etkileri: Patent Verileri Üzerinde Bir Uygulama. Paradoks: The Journal of Economics, Sociology \& Politics, 7(2).

Merkez Bankas1. (2019). https://evds2.tcmb.gov.tr (Erişim: 15.01.2019).

Merville, L. J. ve Tavis, L. A. (1973). A Generalized Model for Capital Investment. The Journal of Finance, 28(1), 109-118.

Mosheiov, G. ve Raveh, A. (1997). On Trend Estimation of Time-Series: A Simple Linear Programming Approach. Journal of The Operational Research Society, 48(1), 90-96.

Narayan, P. K. ve Narayan, S. (2005). Estimating Income and Price Elasticities of Imports for Fiji in A Cointegration Framework. Economic Modelling, 22(3), 423-438.

Pedroni, P. (1996). Fully Modified OLS for Heterogeneous Cointegrated Panels and The Case of Purchasing Power Parity. Manuscript, Department of Economics, Indiana University, 1-45.

Pesaran, M. H., Shin, Y. ve Smith, R. J. (2001). Bounds Testing Approaches to The Analysis of Level Relationships. Journal of Applied Econometrics, 16(3), 289-326.

Phillips, P. C. ve Perron, P. (1988). Testing for A Unit Root in Time Series Regression. Biometrika, 75(2), 335-346.

Porter, M. E. ve Stern, S. (2000). Measuring The "Ideas" Production Function: Evidence from International Patent Output (No. w7891). National Bureau of Economic Research. 
Sheth, J. (1986). Global Markets or Global Competition. Journal of Consumer Marketing, 3(2), 9-11.

Shumway, C. R. ve Chang, A. A. (1977). Linear Programming Versus Positively Estimated Supply Functions: An Empirical and Methodological Critique. American Journal of Agricultural Economics, 59(2), 344-357.

Sledzik, K. (2013). Schumpeter's View On Innovation and Entrepreneurship. Management Trends in Theory and Practice. University of Zilina \& Institute of Management.

Sungur, O., Aydın, H. ve Eren, M. (2016). Türkiye'de Ar-Ge, İnovasyon, İhracat ve Ekonomik Büyüme Arasındaki İlişki: Asimetrik Nedensellik Analizi. Süleyman Demirel Üniversitesi İktisadi ve İdari Bilimler Fakültesi Dergisi, 21(1), 173-192.

Tarı, R. ve Yıldırım, D. Ç. (2009). Döviz Kuru Belirsizliğinin İhracata Etkisi: Türkiye İçin Bir Uygulama. Yönetim Ve Ekonomi: Celal Bayar Üniversitesi Iktisadi ve İdari Bilimler Fakültesi Dergisi, 16(2), 95-105.

TPE. (2019). https://www.turkpatent.gov.tr/TURKPATENT/statistics (Erişim: 14.03.2019).

TÜİK. (2018). http://www.tuik.gov.tr/UstMenu.do?metod=kategorist (Erişim: 20.12.2018).

Tüylüoğlu, Ş. ve Saraç, Ş. (2012). Gelişmiş ve Gelişmekte Olan Ülkelerde İnovasyonun Belirleyicileri: Ampirik Bir Analiz. Eskişehir Osmangazi Üniversitesi İktisadi ve İdari Bilimler Dergisi, 7(1), 39-74.

Varsakelis, N. C. (2001). The Impact of Patent Protection, Economy Openness and National Culture On R\&D Investment: A Cross-Country Empirical Investigation. Research Policy, 30(7), 1059-1068.

Weerawardena, J. ve Mavondo, F. T. (2011). Capabilities, Innovation and Competitive Advantage. Industrial Marketing Management, 40(8), 1220-1223.

Worldbank. (2020). https://data.worldbank.org (Erişim: 30.01.2020). 